\title{
UNIVERSITYOF BIRMINGHAM

\section{A CONCEPTUAL FRAMEWORK FOR UNDERSTANDING THE MECHANISM OF ACTION OF COMMUNITY HEALTH WORKERS SERVICES: THE CENTRALITY OF SOCIAL SUPPORT}

Taylor, Rebecca; Mathers, Jonathan; Parry, Jayne

License:

None: All rights reserved

Document Version

Peer reviewed version

Citation for published version (Harvard):

Taylor, R, Mathers, J \& Parry, J 2017, 'A CONCEPTUAL FRAMEWORK FOR UNDERSTANDING THE

MECHANISM OF ACTION OF COMMUNITY HEALTH WORKERS SERVICES: THE CENTRALITY OF SOCIAL SUPPORT', Journal of Public Health.

Link to publication on Research at Birmingham portal

Publisher Rights Statement:

This article has been accepted for publication in Journal of Public Health Published by Oxford University Press.

\begin{abstract}
General rights
Unless a licence is specified above, all rights (including copyright and moral rights) in this document are retained by the authors and/or the copyright holders. The express permission of the copyright holder must be obtained for any use of this material other than for purposes
\end{abstract} permitted by law.

- Users may freely distribute the URL that is used to identify this publication.

- Users may download and/or print one copy of the publication from the University of Birmingham research portal for the purpose of private study or non-commercial research.

- User may use extracts from the document in line with the concept of 'fair dealing' under the Copyright, Designs and Patents Act 1988 (?)

- Users may not further distribute the material nor use it for the purposes of commercial gain.

Where a licence is displayed above, please note the terms and conditions of the licence govern your use of this document.

When citing, please reference the published version.

Take down policy

While the University of Birmingham exercises care and attention in making items available there are rare occasions when an item has been uploaded in error or has been deemed to be commercially or otherwise sensitive.

If you believe that this is the case for this document, please contact UBIRA@lists.bham.ac.uk providing details and we will remove access to the work immediately and investigate. 
A CONCEPTUAL FRAMEWORK FOR UNDERSTANDING THE MECHANISM OF ACTION OF COMMUNITY HEALTH WORKERS SERVICES: THE CENTRALITY OF SOCIAL SUPPORT

Beck Taylor

Post-doctoral Clinical Research Fellow

Jonathan Mathers

Senior Lecturer

Jayne Parry

Professor

All Authors:

Institute of Applied Health Research

University of Birmingham

Edgbaston

Birmingham

England, UK

B15 2TT

Corresponding Author: Jayne Parry

J.M.Parry.1@bham.ac.uk

+44(0)121 4143191 


\section{ABSTRACT}

\section{Objective}

To propose an empirically-derived and theoretically-informed mechanism to explain how Community Health Workers (CHWs) bring about health gain in clients in England.

\section{Methods}

We undertook in-depth interviews $(n=43)$ with CHWs and service staff working in four case studies selected using maximum variation sampling. Interviewees were encouraged to talk about the service, how they had become involved with the service, the CHW role and relationship with clients.

\section{Findings}

We identified the provision of social support to be central to the mechanism of CHWmediated health gain. Appropriate social support provision comprised three inter-related elements; needs assessment, social support delivery, and client engagement. This mechanism is dependent on the personal characteristics of CHWs and of the roles they are employed or volunteer to carry out.

\section{Conclusion}

A range of CHW characteristics can influence the social support process, but these are context-dependent and move beyond simple notions of CHW similarity to the client. This finding has important policy implications for the development and implementation of CHW services in high income countries with super-diverse populations. 


\section{INTRODUCTION}

"As the need for CHWs continues to rise, it will also be important to understand the desired attributes of the CHW applicants. Further study is needed to determine whether particular attributes are correlated with intervention efficacy, to inform training and credentialing, as well as reimbursement structures" [1]

The first official United States (US) Community Health Workers (CHWs) were put in place in the 1960s to serve the needs of Native American communities [2]. It is now estimated that there are 175,000 workers operating in the country, one-quarter of which are volunteers [3]. Workers address a wide range of issues, but their focus is generally on 'underserved' populations, with an aim of minimising health disparities (referred to as inequalities in the English context) [4]. There has been growing recognition of the value of the CHW role in the US, and significant efforts have been made to document the role and its characteristics.

States including Massachusetts and Minnesota have formalised and industrialised the role, recognising it in state health care provision [5]. Similar policy actions are now being observed elsewhere in the US, not least as a result of CHWs being explicitly cited in the Affordable Care Act, as part of an approach to improve healthcare access, reduce costs, and improve quality [6].

In contrast to the US, in England CHWs have not been recognised as a coherent occupational group and implementation of services has been variable across the nation. The slower evolution of CHW approaches is perhaps a result of the inception of a well-resourced universal health care system in England in the middle of the twentieth century. In the past 20 years however there has been an increasing recognition of the need to address risk factors for poor health in England in addition to providing health services [7,8]. Academics and policymakers identified that for the population to achieve optimum health and wellbeing, and to prevent unaffordable rises in health and social care cost, individuals would have to be 'fully engaged' in managing their own health [9]. CHWs are seen as a potential resource to assist individuals in managing their own health and lifestyle risks. There has also been an increased focus on addressing inequalities in health, and CHW approaches have been proposed as part of the solution $[8,10]$. These factors have resulted in a range of CHW services being implemented at local and national level [11,12]. These services have varying characteristics; for example, some are delivered by salaried workers, others by unpaid volunteers; some workers may undergo some formal training, others none relying instead on 
their lived experiences to help others. Thus under the CHW umbrella are a spectrum of activities which include, for example, volunteer Expert Patients [13], to more formally trained and salaried Health Trainers [14] and Care System Navigators [15].

Despite the expansion of CHW services, evidence of their effectiveness in high income countries remains unclear $[1,16,17]$. Further our understanding of the mechanism/s by which CHWs may act as agents of population health improvement is limited. This understanding is important for it is only through knowledge of the 'active ingredients' and their mechanism of action that we can design more effective interventions and target the most effective deployment of services across different client groups and settings [18]. At present recruitment and deployment of CHWs is often guided by assumptions of the need for workers to be 'the person next door' who is 'similar in some ways to their clients and so 'understand' why they may not wish to engage with existing services. While such assumptions may be intuitively appealing, they have not been adequately justified through appropriate theorising and empirical analyses.

We have used interview data gathered from four diverse CHW services in England and iteratively synthesised with the literature to propose a taxonomy of person and role characteristics which appear to impact on CHW effectiveness [19]. In this paper, we re-visit our data to surface a common mechanism for CHW-mediated health gain, and argue that worker effectiveness depends critically on the characteristics contained within the taxonomy.

\section{METHODS}

\section{In-depth Case Studies of Community Health Worker Services}

\section{Sampling Frame}

As noted above, in England CHWs have not been recognised as a coherent occupational group and there is therefore no (to our knowledge) agreed formal definition for the role. As Olaniran and colleagues note [20], this "make[s] it difficult for policy makers, programme planners, and researchers working with CHWs in different settings to have a common understanding of 'who is a CHW?'

In this study we opted for a pragmatic definition and included in our sampling frame services with workers who were non-professions (i.e. not a doctor or nurse) and who were not 
clinically qualified (i.e. excluding workers who have had some clinical training, e.g. Health Care Assistants or Maternity Support Workers) who were undertaking any work to promote health with NHS patients or community members. The health promotion could include behaviour change or other types of non-clinical support designed to improve health and wellbeing.

\section{Selection of Case Studies}

Case studies were purposively selected to capture a range of CHW models and client populations operating in England. Thus we deliberately selected services such that we covered a spectrum of characteristics, including; whether workers were paid or volunteers, group and individual interventions, National Health Service (NHS) and non-NHS providers, single (e.g. breastfeeding) and complex (e.g. multiple pregnancy outcomes) issues. With respect to the target population we sought urban and rural/non-urban, deprived and affluent, diverse and homogeneous populations. The summary characteristics of the four case studies selected are presented in Table 1.

\section{Ethical Approval}

The work was approved by South Birmingham Ethics Committee, reference 10/H1207/74.

\section{Data Collection}

BT conducted in-depth individual interviews with workers and service managers within the selected services. Up to $10 \mathrm{CHW}$ participants were interviewed in each case study, though in some services fewer were available (Table 2). All available managers were interviewed in each service, plus a small number of stakeholders in partner organisations. All participants were female.

The initial part of each interview was deliberately unstructured in order to allow the interviewee to 'tell their story'. Interviewees were encouraged to talk about the service, how they had become involved with the service, and the CHW role and relationship with clients. Direct questions were avoided until the near end of an interview and only introduced then if a key point of interest had not been volunteered or addressed. The interviews were conducted between November 2011 and September 2012. 


\section{Analysis of Interviews}

Interviews were audio-recorded and transcribed verbatim for analysis. BT conducted the initial thematic analysis of their content based on the Framework analytic approach [21]. After initial familiarisation, coding, indexing and thematic development proceeded iteratively with on-going discussion among all authors. The analyses presented here focus on our comparative findings across the individual case study services, including recurrent cross-case observations and themes.

\section{FINDINGS: HOW DO CHWS MEDIATE HEALTH GAIN IN CLIENTS}

Figure 1 presents our framework for understanding $\mathrm{CHW}$-mediated health improvement. Central is the concept of social support which has three inter-related elements: identification and assessment of the client's support needs; provision of appropriate social support; and client engagement with the support offered. In the following section we provide examples of how characteristics (in italics) identified in the taxonomy we developed from these data and reported previously [19; Box 1] shape a CHW's ability to deliver these three activities.

\section{Needs Assessment}

Identification of client needs requires an understanding of the client's situation, and what can be done to help. CHWs' person characteristics influence this; for example, the Make and Taste Workers knew that their clients were on a low income, and often had very limited access to kitchen equipment and facilities (knowledge - population knowledge). Therefore, the clients needed support that did not require them to buy expensive ingredients, or to use equipment they did not have. The CHWs' personal qualities such as empathy or being nonjudgmental also influenced the information-gathering process. The following quote illustrates how a Pregnancy Outreach Worker’s (POW) ability to empathise with a client led her to interpret her needs differently; she did not perceive stopping smoking to be a priority in light of the client's wider situation. 
"Knowing that, you know, other things that people think, you know it's dreadful that a pregnant woman smokes, yeah you know, it's not ideal, we all know smoking is bad for you, they know that smoking is bad for you, but actually you know, in the scheme of things, when your life's in chaos, the last thing that you are going to be concerned about is stop smoking, you know, and it's just to have that understanding of where people are in their lives and not judging people for choosing a certain lifestyle I think.” (Pregnancy Outreach Worker 7).

Role characteristics also influence needs assessment. Continuity of worker was reported to provide a better opportunity to build a picture of their clients over time, without the need to start afresh with each client interaction. The setting where support was provided was also described as impacting on the quality of needs assessment, particularly, when the venue for support was the client's own home. The core tasks and enacted philosophy of the CHW services led to workers focusing specifically on what the client felt they needed, what they wished to achieve, and any perceived barriers.

"And sometimes it might not even be really talking; it's just listening. It's just about assessing that mum and finding out ultimately what she wants to get out from that situation. So she comes and she says, 'X, Y, Z,' and you'll say, 'Well, what do you want to achieve?' Because some mums will come in and have certain situations and you're not even quite sure that they want to breast...it's almost like they want to get outdoors. And that's fine, if you choose not to breastfeed your baby, nobody's going to...we're not the Breastapo, as they like to label us. We're not going to make you breastfeed a baby if you don't want to, because if you don't want to do it, it's never going to work anyway.” (Breastfeeding Peer Supporter 5)

\section{Appropriate Delivery of Social Support}

The range of activities undertaken by CHWs to address client needs have been reported in our taxonomy paper. We conceptualise these activities, common to all four case studies, to be forms of social support, though this term was rarely used by participants.

Social support has been defined as "the resources and interactions provided by others that may be useful for helping a person cope with a problem” [22]. In our work we draw on the framework proposed by Langford et al which defines four domains of social support [23]; examples of each is shown in Table 3.

The relationship between CHW person and role characteristics and the provision of social support depends on the type of support being provided. It is self-evident that CHW 
knowledge is important for the delivery of informational support but other characteristics are also relevant. For example, communication skills helped CHWs to deliver the information in an understandable way, similarity meant that workers could share relevant information about their own experiences, and continuity was reported to provide consistent, non-conflicting information. In the example below the interviewee explains how the personal qualities of a CHW (here, empathy and compassion) motivate workers to provide instrumental support:

"It matters to a degree where you come from, how much of yourself you can give of a thing like this but I think at the same time it's down to the individual, is that part of your psyche, your makeup, whatever it is? Do you care enough to care about somebody who ain't got enough money to go and ring up the Social Services? Firstly can you empathise why somebody is in that situation in the first place?" (Pregnancy Outreach Worker 2)

While all the CHW characteristics are associated with appraisal support, the importance of similarity to the client group is particularly prominent. Where a CHW was demographically similar to their client, she could be a valid social comparator, demonstrating traits or sharing stories that enabled social comparison. For example, Slimming World Consultants were encouraged to produce display boards detailing their own weight loss journey. However, similarity between client and worker may not be immediately apparent and may have to be deliberately disclosed to provide an opportunity for social comparison. A number of POWs described sharing certain experiences (such as being a parent) with clients but they also reported not disclosing other issues (such as domestic violence) because they did not wish to share potentially stigmatising experiences, or reveal details that might identify their family.

Emotional support includes providing appreciation, encouragement and reassurance to improve self-esteem [23]. In the following quote a POW manager describes how a worker's knowledge about the lived experience of clients impacts on these messages.

"It's easy if you haven't been there to say, 'Well, leave him, leave him if he's beating you,' and actually, if you know what that's like, it's your - first of all he's sorry afterwards, and he makes you feel good and no-one else does, you've got your kids and their house and their bedrooms and the things that they hold dear and all of those things mean that you don't walk away.” (Pregnancy Outreach Worker Manager 1)

Burleson has explored emotional support and emotionally supportive communication, and outlined how individuals delivering emotional support require specific knowledge and skills 
('competence factors') [8]. He argues emotional support's effectiveness is associated with the degree of 'person-centeredness' of support, that is, "the extent to which messages explicitly acknowledge, elaborate, legitimize, and contextualise the distressed other's feelings and perspective.” [24] Emotionally supportive communication methods may be of low, moderate and high person-centredness, with the latter being the most positively valued by recipients.

Our data suggests that CHWs report consistently adopting highly person-centred approaches to communication with their clients. CHWs related their ability to communicate effectively with knowledge which was either naturally acquired on account of some degree of similarity with clients, or gained through training or experience. However it was also suggested that personal qualities such as empathy and compassion might make up for deficiencies in knowledge. This concurs with Burleson's observation that while shared demographic characteristics are associated with improved recipient-rated emotional support quality, they usually explain only a very small element of the variation in the recipient's evaluation of support. Other factors, especially the support provider's values and personal qualities, appear more important.

\section{Client Engagement}

We conceptualise client engagement as a form of client behaviour, and used Michie and West’s COM-B framework, which posits behaviour (here, case client engagement) to be a function of client capability, opportunity and motivation [25].

Influences on capability can be physical (e.g. physical impairment might prevent exercise), or psychological (e.g. cognitive difficulties might make household budgeting difficult).

Opportunity can be social (e.g. in communities where nobody breastfeeds this can limit exposure to and uptake of breastfeeding) or environmental (e.g. healthy eating is difficult where there are no local shops selling fresh produce). Person and role characteristics enable capability barriers to engagement to be overcome; for example CHWs related how psychological barriers prevented clients leaving the house: workers addressed this by building client self-esteem and capability through emotional and appraisal support (social support). 
CHW characteristics allow them to address a lack of opportunity to engage. For example Peer Supporters, due to their similarity to clients (currently breastfeeding) were able to role model breastfeeding, where there was otherwise no social opportunity for clients to see it within their natural social network. The design of CHW services may overcome a lack of environmental opportunity, for example some workers were able to be flexible in venue for meetings with clients, seeing them at home where a lack of material resources or access to transport made attending other venues difficult.

The conceptualisation of motivation in the COM-B model postulates two separate influences on individual motivation: the reflective (conscious) and automatic (unconscious). Motivation is primarily influenced by automatic, unconscious processes which operate to serve our immediate desire for pleasure or relief; we do what makes us feel good and avoid things which make us feel uncomfortable. Secondary, conscious 'reflective' processes can only influence our behaviour if the automatic processes allow.

Automatic processes are influenced by our emotional responses to stimuli (e.g. anxiety), past associative learning (e.g. that the behaviour was unpleasant before), and by our current drives (in particular our identity; e.g. 'I am a good mother'). These processes are immediate, and do not involve evaluation of alternative options or the consequences of behaviour. For example, a client may consciously evaluate the benefits of attending a Make and Taste group, and may intend to go, but her immediate need to avoid the anxiety caused by meeting unfamiliar people may prevent her from going. The need to avoid psychological discomfort among clients is prominent in our interview data. CHWs reported that they evoked less anxiety and fear in clients compared with traditional professionals, enabling better worker-client relationships. This was often attributed to similarities between workers and clients, and an anxiety about engaging with professionals.

Automatic motivation is improved where engaging in an activity is consistent with, or enhances one's identity or self-concept, and we avoid behaviours which challenge our identity. The CHW characteristics associated with appropriate needs assessment and social support provision were variably reported to enable the worker to understand the nature of the client self-concept, and the need to maintain identity. For example, interviewees often related how they knew that clients did not wish to be told what to do (thanks to their knowledge, 
empathy and/or similarity), indicating that doing otherwise would challenge the client's identity as an autonomous, in-control individual. Workers are able to communicate in a way that avoids this, thanks to their communication skills, and enacted philosophy of client empowerment and this was explicitly contrasted with a more directive approach that professionals were perceived as taking.

Conscious, reflective influences on client motivation to engage with CHWs were also reported, especially that of credibility; that is clients have to perceive that the CHW knows what they are talking about, understands them and their situation, and has the skills and resources to deliver the help that they need. In our data, the CHWs' accounts of positive first impressions and credibility refer to similarity between worker and client. This was described to result in the client perceiving that the worker will have the knowledge, and empathy to understand their situation. Some similarity was passively disclosed to clients (physical attributes might indicate ethnic group), while other characteristics were more actively 'managed' (some workers indicated their non-professional similarity by avoiding wearing smart clothes).

However, there are also accounts where participants suggested that similarity is not essential, as long as other characteristics are evident. For example, in the Make and Taste Service, the Children's Centre venue was valued and trusted by local parents, increasing the likelihood that they would engage. The continuity and time available to many CHWs also affords them a longer period over which to demonstrate credibility than is often available for professional healthcare workers:

"One lady she got her money, carpeted up the whole house...So when you give them advice they're happy to take it from you because you've got that trusting thing, 'Everything you've done for me so far has worked out so I can trust you, anything you said you were going to do, you've done. You've changed my situation for me when you first come to how it is now so I can trust you."” (Pregnancy Outreach Worker 2)

\section{DISCUSSION}

\section{Main finding of this study}

The literature on CHWs is substantial but the mechanism of action of these services is difficult to assess given the heterogeneity of studies which draw on diverse and sometimes 
under-specified conceptual and theoretical foundations [16, 17, 26-28]. In this paper we have sought to address this. Our analyses are informed by established social support and by behavioural theories and we propose an intervention mechanism - appropriate social support provision (comprising needs assessment and social support delivery) and client engagement common across all case studies. This mechanism is dependent on the characteristics of CHWs and the roles they are employed or volunteer to carry out.

\section{What is already known on this topic}

Oher authors have referred to CHWs as delivering social support and improving client engagement but the fine details regarding what these processes involve is lacking [16, 17, 2932]. For example, Durant et al, note that CHWs provide social support, but not why CHWs may be well-placed to do so [31]. Katigbak et al has suggested that the key mediator of health improvement is the adoption of healthy behaviours by clients. This behaviour change is influenced by four aspects of CHW activity: direct behaviour change assistance, leveraging of 'cultural congruence' by CHWs, provision of social support, and the employment of interpersonal communication techniques [29]. Katigbak notes that worker-client characteristics and wider contextual factors (culture, language, immigration and acculturation) influence this process, though in the published work the authors do not specify how [29]. We believe that our proposed mechanism provides a more complete picture of the health improvement process. Further we argue that the provision of social support, presented by Katigbak et al as one of four dimensions of the worker's activities, is actually the primary overarching activity and that of the three other dimensions presented by Katigbak, two (cultural congruence and interpersonal communication techniques) are actually descriptors of CHW characteristics, aligning with our characteristics of similarity and communication skills respectively. We also argue that the third activity (direct behaviour change assistance) falls within the scope of social support. This is because scrutiny of our data reveals that CHWs are not changing behaviour as such, but are providing a range of social support functions whose outcomes include client behaviour change. That the literature frequently concerns itself with behaviour change perhaps betrays the dominance of the medical model; in other words, the problem to be tackled is often conceptualised in terms of the epidemiological need (e.g. for smoking prevalence reduction) rather than the population or client need (e.g. social support which may have a subsequent impact on smoking behaviour) [33]. 
CHW-client similarity has been reported to improve social support provision by making workers more culturally competent, and authors describe how workers with shared experience can act as role models or share stories [29, 33-36]. However, statements are frequently made without evidence to support them and others have warned of the inappropriateness of making assumptions about the nature, and relevance of similarity [22, 26]. We have examined dimensions of similarity: Our mechanism for CHW-mediated health gain offers insight into why, and when similarity might be important, also when it may not be so essential. Where similarity appears not to be essential, it may be because it has no specific function in the particular mechanism being delivered or as we suggest, because other person and role characteristics can compensate. Thus, key to the understanding of the importance of similarity in our model is that it is perceived rather than actual similarity which is important, and that this is subjective, fluid and unlikely to be completely predictable. This observation has been noted elsewhere in the healthcare literature; for example Shiner has reported that while shared experience or demographics may result in shared identity between client and worker, identity is a flexible concept, with individuals being capable of holding a number of identities, the relative importance of each varying depending on the situation, with none taking absolute priority. [37]. Evidence from the doctor-patient demographic concordance literature suggests that while crude definitions of similarity (for example age, ethnicity) are associated to some degree with an improved relationship, it is what Street et al call 'perceived personal similarity' that is the real predictor of an effective relationship. [38]. Perceived personal similarity reflects patients' sense that they share beliefs, values and communication style with their doctor, and this is associated with increased trust, satisfaction, and intention to adhere to medication.

\section{What this study adds}

We have described the activities undertaken by CHWs and argue that they can be conceptualised as one or more domains of social support. Following on, we suggest that for social support to be effective, appropriate needs assessment, support delivery and client engagement are necessary. We have used a range of theories to explore how the person and role characteristics of CHWs identified by participants may act to enable a CHW service to work with clients successfully. While there are many insights into these ideas in the existing literature, this work organises and interrogates the concepts in more detail than has been attempted before. These findings have important policy implications for high income super- 
diverse settings where a heterogeneous population makes matching CHWs with similar clients challenging. A more nuanced consideration of 'similarity' alongside other important CHW characteristics may give service developers a greater flexibility in recruitment and service design, and provide theory-informed service delivery. That social support emerged as a core theme in all the case studies, which had been deliberately sampled to maximise variety of service characteristics, suggests the transferability of the health gain mechanism to other health foci (e.g. sexual health, depression and isolation) and populations (e.g younger and older adults)

\section{Limitations of this study}

We relied on the accounts of the workers and their activities without corroboration from clients. Attempts to recruit clients, which our Ethical Committee required to be via the CHW, were unsuccessful. We did not undertake formal observation of CHW interaction with individual clients, though we were able to observe informally a number of group-based activities, which provided some corroboration of interviewee accounts. Further work with clients including direct observation and longitudinal follow-up of individual client-CHW relationships is vital to 'testing' the mechanism we propose. We also note that all participants in the interviews were women. This reflects the female preponderance among workers in the four case study services. Future work is required to hear the views of male CHWs in order to understand their perceptions of their roles and impact in clients. We could not effectively explore CHW activities such as clinical care or community development, or the impact of CHW embeddedness in the client population, as they were not core functions of the participating services. 


\section{REFERENCES}

1. Landers S, Levinson M. Mounting Evidence of the Effectiveness and Versatility of Community Health Workers. American Journal of Public Health. 2016;106(4):591-2.

2. Perez LM, Martinez J. Community health workers: social justice and policy advocates for community health and well-being. Am J Public Health. 2008;98(1):11-4.

3. Perry HB, Zulliger R, Rogers MM. Community Health Workers in Low-, Middle-, and High-Income Countries: An Overview of Their History, Recent Evolution, and Current Effectiveness. Annual Review of Public Health. 2014;35(1):399-421.

4. Snedley B, Stith A, Nelson A. Unequal Treatment: Confronting Racial and Ethnic Disparities in Health Care. Washington DC: Institute of Medicine; 2002.

5. Rosenthal EL, Brownstein JN, Rush CH, Hirsch GR, Willaert AM, Scott JR, et al. Community health workers: part of the solution. Health Aff (Millwood). 2010;29(7):1338-42.

6. US Department of Health and Human Services. Key Features of the Affordable Care Act Washington DC: US Department of Health and Human Services; [updated 18.11.2014; cited 2015 07.04.2015]. Available from: http://www.hhs.gov/healthcare/facts/timeline/.

7. Department of Health. Choosing Health: Making healthy choices easier. London: Department of Health, 2004.

8. Marmot M. The Marmot Review final report: Fair society, healthy lives. London: University College London, 2010

9. Wanless D. Securing good health for the whole population: final report. London: Department of Health, 2004.

10. Wilkinson R, Pickett K. The Spirit Level: Why More Equal Societies Almost Always Do Better. London: Allen Lane; 2009.

11. NHS Confederation. Community health champions: creating new relationships with patients and communities. London: NHS Confederation, 2012.

12. Self Management UK. Who we are 2013. Available from: http://selfmanagementuk.org/who-we-are.

13. https://www.gov.uk/government/case-studies/the-expert-patients-programme; accessed April 72017

14. Department of Health (2004). Choosing Health: Making Healthier Choices Easier. Department of Health, London: 16 November 2004 
15. Health Education England. Care navigation: a competency framework. https://hee.nhs.uk/sites/default/files/documents/Care\%20Navigation\%20Competency\% 20Framework_Final.pdf; accessed April 82017

16. Carr S, Lhussier M, Forster N, Geddes L, Deane K, et al. (2011) An evidence synthesis of qualitative and quantitative research on component intervention techniques, effectiveness, cost-effectiveness, equity and acceptability of different versions of health-related lifestyle advisor role in improving health. Health Technol Assess 15(09).

17. Kim K, Choi J, Choi E et al. Effects of Community-Based Health Worker Interventions to Improve Chronic Disease Management and Care among Vulnerable populations: A Systematic Review. Am J Public Health 2016; 106 (4): e3-e28

18. Medical Research Council. Developing and evaluating complex interventions: new guidance. London: 2008.

19. (ANONYMISED) __ _ _ _ Who are community health workers and what do they do? Development of an empirically-derived reporting taxonomy. In press (Journal of Public Health -16-0428.R2; OUP proof: 10.1093/pubmed/fdx033.

20. Olaniran A, Smith H, Unkels R, Bar-Zeev, van den Broek N. Who is a community health worker? - a systematic review of definitions. Global Health Action_2017; 10 (1) 1272223 (published online at http://www.tandfonline.com/doi/full/10.1080/16549716.2017.1272223)

21. Ritchie J, Lewis J, McNaughton-Nicholls C, Ormston R. Qualitative Research Practice: A Guide for Social Science Students and Researchers. 2 ed. London: SAGE; 2013.

22. Simoni JM, Franks JC, Lehavot K, Yard SS. Peer Interventions to Promote Health: Conceptual Considerations. The American journal of orthopsychiatry. 2011;81(3):3519

23. Langford CPH, Bowsher J, Maloney JP, Lillis PP. Social support: a conceptual analysis. Journal of Advanced Nursing. 1997;25(1):95-100

24. Burleson BR. The experience and effects of emotional support: What the study of cultural and gender differences can tell us about close relationships, emotion, and interpersonal communication. Personal Relationships. 2003;10(1):1-23

25. Michie S, van Stralen MM, West R. The behaviour change wheel: A new method for characterising and designing behaviour change interventions. Implementation Science 2011; 6:42

26. Arvey SR, Fernandez ME. Identifying the core elements of effective community health worker programs: a research agenda. Am J Public Health. 2012;102(9):1633-7

27. Lewin SA, Dick J, Pond P, Zwarenstein M, Aja G, van Wyk B, et al. Lay health workers in primary and community health care. Cochrane Database Syst Rev. 2005(1):CD004015. 
28. South J WJ, Gamsu M. People-centred Public Health. Bristol: Policy Press; 2013.

29. Katigbak C, Van Devanter N, Islam N, Trinh-Shevrin C. Partners in Health: A Conceptual Framework for the Role of Community Health Workers in Facilitating Patients' Adoption of Healthy Behaviors. American Journal of Public Health. 2015;105(5):872-80.

30. Hoddinott P, Chalmers M, Pill R. One-to-One or Group-Based Peer Support for Breastfeeding? Women's Perceptions of a Breastfeeding Peer Coaching Intervention. Birth. 2006;33(2):139-46.

31. Durant RW, Brown QL, Cherrington AL, Andreae LJ, Hardy CM, Scarinci IC. Social support among African Americans with heart failure: Is there a role for community health advisors? Heart \& Lung: The Journal of Acute and Critical Care. 2013;42(1):1925.

32. Ingram M, Torres E, Redondo F, Bradford G, Wang C, O'Toole ML. The impact of promotoras on social support and glycemic control among members of a farmworker community on the US-Mexico border. Diabetes Educ. 2007;33 Suppl 6:172s-8s

33. Graham H. Women and smoking: understanding socioeconomic influences. Drug Alcohol Depend. 2009 Oct 1;104 Suppl 1:S11-6

34. Larkey LK, Alatorre C, Buller DB, Morrill C, Klein Buller M, Taren D, et al. Communication strategies for dietary change in a worksite peer educator intervention. Health Educ Res. 1999;14(6):777-90.

35. Lucio RL, Zuniga GC, Seol YH, Garza N, Mier N, Trevino L. Incorporating what promotoras learn: becoming role models to effect positive change. J Community Health. 2012;37(5):1026-31.

36. Jacobson N, Trojanowski L, Dewa CS. What do peer support workers do? A job description. BMC Health Serv Res. 2012;12:205

37. Shiner M. Defining peer education. Journal of Adolescence. 1999;22(4):555-66

38. Street RL, O’Malley KJ, Cooper LA, Haidet P. Understanding Concordance in PatientPhysician Relationships: Personal and Ethnic Dimensions of Shared Identity. Ann Fam Med 2008; 6(3): 198-205 
Table 1: Description of Case Studies

\begin{tabular}{|c|c|c|c|c|}
\hline & Staff & Client group & Venue & Nature of support \\
\hline $\begin{array}{l}\text { Pregnancy } \\
\text { Outreach } \\
\text { Worker (POW) } \\
\text { Service }\end{array}$ & $\begin{array}{l}\text { Salaried staff } \\
\text { with } \\
\text { 'community } \\
\text { experience' }\end{array}$ & $\begin{array}{l}\text { Pregnant women at } \\
\text { high social risk } \\
\text { Predominantly referred } \\
\text { by health } \\
\text { professionals. }\end{array}$ & $\begin{array}{l}\text { Flexible: homes, } \\
\text { health and social } \\
\text { care settings, } \\
\text { community } \\
\text { settings }\end{array}$ & $\begin{array}{l}\text { 1:1 support until } 8 \text { weeks } \\
\text { post-birth, tailored to } \\
\text { client, includes benefits } \\
\text { advice, lifestyle support, } \\
\text { liaising with professional, } \\
\text { providing transport }\end{array}$ \\
\hline $\begin{array}{l}\text { Breastfeeding } \\
\text { Peer Supporter } \\
\text { (BFPS) Service }\end{array}$ & $\begin{array}{l}\text { Volunteers } \\
\text { All have } \\
\text { breastfed/are } \\
\text { breastfeeding }\end{array}$ & $\begin{array}{l}\text { Pregnant and } \\
\text { breastfeeding women } \\
\text { Professional and self- } \\
\text { referral }\end{array}$ & $\begin{array}{l}\text { Breastfeeding } \\
\text { ‘cafés' in } \\
\text { children's centres* } \\
\text { and community } \\
\text { venues }\end{array}$ & $\begin{array}{l}\text { Primarily drop-in group } \\
\text { based advice and support, } \\
\text { plus antenatal } \\
\text { breastfeeding classes and } \\
\text { promotional work }\end{array}$ \\
\hline $\begin{array}{l}\text { Make \& Taste } \\
\text { (M\&T) Service }\end{array}$ & $\begin{array}{l}\text { Sessional } \\
\text { workers (paid } \\
\text { per session) } \\
\text { Some existing } \\
\text { cooking and } \\
\text { nutrition skill }\end{array}$ & $\begin{array}{l}\text { Parents with young } \\
\text { children in low income } \\
\text { community Some } \\
\text { work with socially } \\
\text { excluded adults } \\
\text { Mixture of } \\
\text { professional and self- } \\
\text { referral }\end{array}$ & $\begin{array}{l}\text { Children’s } \\
\text { centres* }\end{array}$ & $\begin{array}{l}\text { Nutrition and cookery } \\
\text { groups for parents and } \\
\text { vulnerable adults } \\
6 \text { weekly sessions } \\
\text { Childcare provided }\end{array}$ \\
\hline $\begin{array}{l}\text { Slimming World } \\
\text { (SW) }\end{array}$ & $\begin{array}{l}\text { Independent } \\
\text { franchise } \\
\text { holders } \\
\text { All have been } \\
\text { clients in the } \\
\text { past }\end{array}$ & $\begin{array}{l}\text { Overweight or obese } \\
\text { individuals Mostly } \\
\text { self-referral with some } \\
\text { referred by health } \\
\text { service using vouchers }\end{array}$ & $\begin{array}{l}\text { Community } \\
\text { venues e.g. church } \\
\text { halls }\end{array}$ & $\begin{array}{l}\text { Group based weight loss } \\
\text { support } \\
\text { Measuring weight, } \\
\text { providing advice and } \\
\text { resources, leading group }\end{array}$ \\
\hline
\end{tabular}

*Government-funded centres which give help and advice on child and family health, parenting, money, training and employment, and which are open to all parents, carers and children 
Table 2: Interviewee recruitment

\begin{tabular}{|c|c|c|c|c|}
\hline Case study & $\begin{array}{l}\text { Type of } \\
\text { participant }\end{array}$ & $\begin{array}{l}\text { Number } \\
\text { recruited }\end{array}$ & $\begin{array}{l}\text { Number } \\
\text { available }\end{array}$ & Notes \\
\hline \multirow{3}{*}{$\begin{array}{l}\text { Pregnancy } \\
\text { Outreach } \\
\text { Worker } \\
\text { (POW) } \\
\text { Service } \\
\end{array}$} & Salaried worker & 10 & 34 & \\
\hline & Manager & 5 & 5 & \\
\hline & Other & 2 & N/A & 2 commissioners \\
\hline \multirow{3}{*}{$\begin{array}{l}\text { Breastfeeding } \\
\text { Peer } \\
\text { Supporter } \\
\text { (BFPS) } \\
\text { Service } \\
\end{array}$} & Volunteer worker & 10 & $\begin{array}{l}\text { Total volunteer } \\
\text { pool unknown }\end{array}$ & \\
\hline & Manager & 2 & 2 & \\
\hline & Other & 2 & N/A & Other stakeholder \\
\hline \multirow{3}{*}{$\begin{array}{l}\text { Make \& } \\
\text { Taste (M\&T) } \\
\text { Service }\end{array}$} & Sessional worker & 4 & 3 & 1 also a manager \\
\hline & Manager & 2 & 2 & \\
\hline & Other & 1 & N/A & Other stakeholder \\
\hline \multirow[t]{3}{*}{$\begin{array}{l}\text { Slimming } \\
\text { World }\end{array}$} & $\begin{array}{c}\text { Self-employed } \\
\text { worker }\end{array}$ & 3 & 7 & \\
\hline & Manager & 2 & 2 & \\
\hline & Other & - & N/A & \\
\hline \multirow[t]{3}{*}{ Total } & Workers & 27 & & \\
\hline & Manager & 11 & & \\
\hline & Other & 3* & N/A & \\
\hline \multicolumn{2}{|l|}{ Grand total } & 43 & & \\
\hline
\end{tabular}

*One 'other' interviewee was associated with two services and thus although interviewed only once, provided information about two case studies. 
Figure 1: Diagram representing proposed mechanism of CHW-mediated client impact

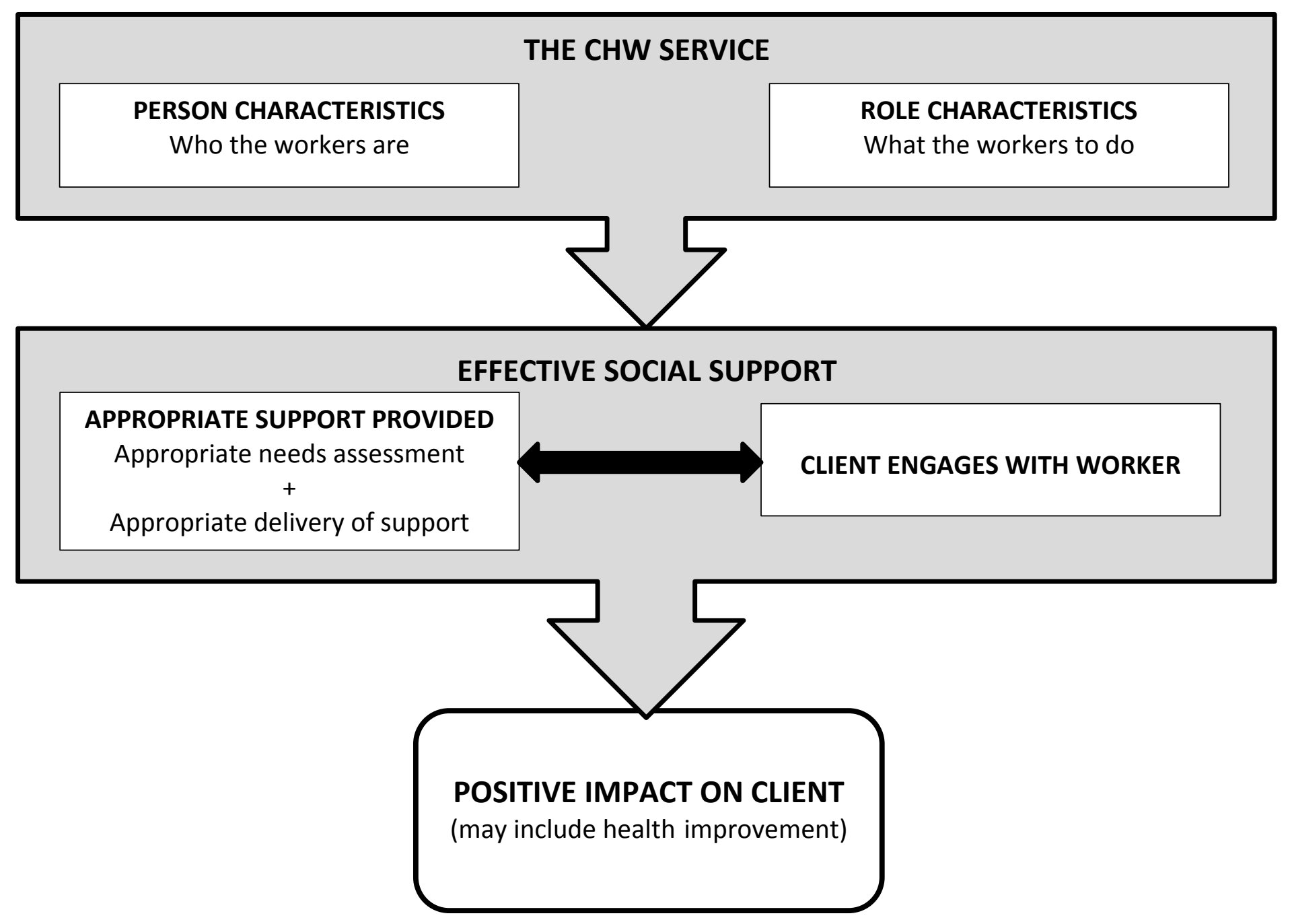




\section{Box 1: Summary of CHW Person and Role Characteristics}

\section{TAXONOMY OF COMMUNITY HEALTH WORKER CHARACTERISTICS}

\section{PERSON CHARACTERISTICS}

(1) KNOWLEDGE AND SKILLS

\section{(1.1) Knowledge}

Population knowledge

Specialist knowledge

Service knowledge

\section{(1.2) Skills}

Communication

Community language

Specific skills

(2) Personal Qualities

People person+

Empathic and compassionate

Values and attitudes

Non-judgmental

Persistent

Goes the extra mile

Appropriate disposition

\section{'WHO WORKERS ARE'}

\section{What knowledge do workers possess?}

Local people and their lives and experiences

Note 'local' people may be highly heterogeneous

The local area (geography, facilities etc)

Health (e.g. diabetes, pregnancy)

Social care (e.g. domestic violence, child protection)

Behaviour (e.g. breastfeeding, smoking)

Local public, private and third sector service provision and access, including previous personal use of the CHW service as a client

\section{What skills do workers possess?}

Listening, explaining etc.

e.g. Urdu

e.g. breastfeeding, cookery

\section{WHAT SORT OF PERSON IS SUITABLE FOR THIS ROLE?} Enjoys working with people

Able to see the world from others' viewpoint Caring

Values may influence support, e.g. if pro-breastfeeding worker may withhold information on formula feeding. Need to be clear what is/is not acceptable.

Accepts and respects clients regardless of their characteristics or behaviour

Pursues tasks in the face of barriers

Willing to make additional effort to help clients, goes further than obligated to by employer (e.g. stays until job is done)

Is friendly, warm, positive etc. 


\begin{tabular}{|c|c|}
\hline $\begin{array}{l}\text { (3.1) Shared demographic characteristics } \\
\text { Gender }\end{array}$ & Self-explanatory \\
\hline Age & $\begin{array}{l}\text { Defining a specific age range may be challenging } \\
\text { Note that individuals experience different life events at } \\
\text { different ages }\end{array}$ \\
\hline Locality of residence & $\begin{array}{l}\text { Definitions can be administrative, or neighbourhood-based } \\
\text { (i.e. client-defined) } \\
\text { Individuals who live in the same area may not identify as } \\
\text { belonging to the same community }\end{array}$ \\
\hline Socioeconomic status & $\begin{array}{l}\text { May be defined along economic, educational, occupational or } \\
\text { 'class' lines. } \\
\text { Note that these characteristics are not fixed and workers may } \\
\text { change e.g. through social mobility }\end{array}$ \\
\hline Ethnicity & $\begin{array}{l}\text { Note that administrative definitions of ethnicity which may be } \\
\text { broad, or may not match individuals' self-defined ethnicity. } \\
\text { Ethnic 'communities' may be diverse } \\
\text { Note that migrant and locally-born individuals may differ } \\
\text { despite ethnic similarity }\end{array}$ \\
\hline Religion & $\begin{array}{l}\text { Note broad definitions may not account for differences within } \\
\text { faiths, e.g. Shia and Sunni Muslims }\end{array}$ \\
\hline (3.2) Shared experience & $\begin{array}{l}\text { Note that 'experience' has many dimensions, e.g. some find } \\
\text { breastfeeding easy while others face huge challenges } \\
\text { Note that it may be important whether or not experience is } \\
\text { recent }\end{array}$ \\
\hline (3.3) Shared non-professional status & $\begin{array}{l}\text { The term 'lay' is not used as many CHWs have acquired } \\
\text { knowledge and skills above lay people } \\
\text { Note that clients may still view workers as 'outsiders' from } \\
\text { official organisations, even if they are not professionals }\end{array}$ \\
\hline (4) VOLUNTEER OR PAID & SHOULD WORKERS BE VOLUNTEERS OR PAID? \\
\hline ROLE CHARACTERISTICS & 'WHAT WORKERS DO' \\
\hline (5) TIME AND CONTINUITY OF WORKER & $\begin{array}{l}\text { DO CLIENTS NEED TO SEE THE SAME WORKER AT EACH } \\
\text { CONTACT AND WHEN IS THE WORKER AVAILABLE? } \\
\text { Contact outside of ordinary working hours may be of benefit } \\
\text { Flexible session times may be of benefit } \\
\text { Consider frequency (number of contacts), regularity (how } \\
\text { often contacts occur), duration (how long contact sessions } \\
\text { last), and duration of relationship (how long CHW is involved } \\
\text { in client's life) }\end{array}$ \\
\hline $\begin{array}{l}\text { (6) SETTINGS } \\
\text { (6.1) Geographical location }\end{array}$ & $\begin{array}{l}\text { WHERE AND WHEN IS THE SERVICE BEST PROVIDED? } \\
\text { Proximity to the client's location }\end{array}$ \\
\hline
\end{tabular}


(6.2) Physical venue

(6.3) Group settings

(7) LIMITED RESPONSIBILITY

(8) CORE TASKS (SOCIAL SUPPORT)

(9) ENACTED PHILOSOPHY

(EMPOWERMENT AND CLIENT-FOCUSED

CARE
Clients homes, community venues, etc.

Venues may provide other services e.g. childcare

Group or one-to-one contact may be appropriate

\section{DO WORKERS HAVE A DISCRETE AND WELL-DEFINED} REMIT?

\section{WHAT IS THE SERVICE INTENDED TO DO?}

Informational, instrumental, appraisal and emotional support for the individual client

IS PRIMACY GIVEN TO THE CLIENT'S OWN NEEDS RATHER THAN EPIDEMIOLOGICAL OR SERVICE OBJECTIVES? 
Table 3: Examples of CHW activities mapped to Langford's typology of social support [7]

\begin{tabular}{|c|c|c|c|c|}
\hline & \multicolumn{4}{|c|}{ SOCIAL SUPPORT CATEGORY } \\
\hline & Instrumental & Informational & Emotional & Appraisal \\
\hline $\begin{array}{l}\text { Pregnancy Outreach } \\
\text { Worker (POW) Service }\end{array}$ & $\begin{array}{l}\text { Transporting clients in } \\
\text { car }\end{array}$ & Providing benefits advice & $\begin{array}{l}\text { Listening to clients' } \\
\text { problems }\end{array}$ & $\begin{array}{l}\text { Reflecting on clients' } \\
\text { achievements }\end{array}$ \\
\hline $\begin{array}{l}\text { Breastfeeding Peer } \\
\text { Supporter (BFPS) } \\
\text { Service }\end{array}$ & $\begin{array}{l}\text { Providing a 'safe', } \\
\text { comfortable place to feed } \\
\text { in public }\end{array}$ & $\begin{array}{l}\text { Providing information } \\
\text { about what breastfeeding } \\
\text { is really like }\end{array}$ & $\begin{array}{l}\text { Expressing sympathy to } \\
\text { distressed clients }\end{array}$ & $\begin{array}{l}\text { Encouraging clients to } \\
\text { describe and reflect on } \\
\text { their situation }\end{array}$ \\
\hline $\begin{array}{l}\text { Make \& Taste (M\&T) } \\
\text { Service }\end{array}$ & Providing ingredients & $\begin{array}{l}\text { Providing information on } \\
\text { sugar content of common } \\
\text { foods }\end{array}$ & Giving praise & $\begin{array}{l}\text { Sharing stories of } \\
\text { workers' cookery } \\
\text { mistakes }\end{array}$ \\
\hline Slimming World (SW) & $\begin{array}{l}\text { Providing a weekly } \\
\text { 'weigh in' service }\end{array}$ & Providing dietary advice & $\begin{array}{l}\text { Text message support to } \\
\text { check wellbeing and } \\
\text { encourage }\end{array}$ & $\begin{array}{l}\text { Encouraging others } \\
\text { members to share their } \\
\text { stories }\end{array}$ \\
\hline
\end{tabular}


